\title{
Camel rearing replacing cattle production among the Borana community in Isiolo County of Northern Kenya, as climate variability bites
}

Anastasia W Kagunyu ${ }^{*}$ and Joseph Wanjohi ${ }^{2}$

\begin{abstract}
This study took place in Isiolo County of semi-arid northern Kenya among Borana pastoralists. Current scientific evidence indicates that climate variability is threatening reliance on cattle. This study aimed to understand whether the Borana community would let go their cattle culture and embrace camel production. The results showed that the Borana have changed their preference from cattle to camel rearing. Constraints identified as affecting camel production included the following: diseases, raiding and competition from other livestock. There is need to employ animal health workers to bail out the pastoralists from threats of livestock diseases, and to promote peace in the region.
\end{abstract}

Keywords: Camels; Borana; Livestock species

\section{Introduction}

Camel production is a major source of livelihood for the pastoralists in the arid and semi-arid lands (ASAL) of Kenya, which hosts $6 \%$ of the African camel population (Hulsebusch and Kaufmann 2002). The total population of camels in Kenya was three million, according to the latest census in 2009 as compared to a population of 0.8 million in the 1999 census. This is an indication that the camel population in Kenya has continued to increase despite the effects of climate change. Today, some communities which did not previously keep camels have started rearing some to supplement their cattle production, especially during the dry seasons (Farm Africa 2002).

Camels have been referred to as the desert dairy due to the important roles they play in the ASAL (Field 2005). They are able to survive well in the ASAL due to their biological and physiological adaptations which help them cope with harsh environmental conditions. They drink less water as compared to other livestock species, and they have the ability to stay for many days without water, an ability which they owe to their remarkable tolerance of dehydration while keeping the blood volume normal. Guliye (2010) noted that

\footnotetext{
* Correspondence: kagunyu2010@gmail.com

${ }^{1}$ Socio-economics, Kenya Agricultural Research Institute, P.O. Box 147-60500, Marsabit, Kenya

Full list of author information is available at the end of the article
}

camels in the ASAL of Kenya have a varied diet which includes shrubs and trees. Field (2005) estimated that the volume of milk produced by camels is six times that produced by indigenous cattle found in the dry lands. Despite the important roles played by camels in the pastoral communities of northern Kenya, they have been neglected by scientists, by policymakers and by the government (Field 1994). Farm Africa (2002) has observed that camels have been neglected and underused for a long time. Kuria and Mbui (2001) made similar observations that, despite the advantages the camel has over other domestic animals, it has been neglected, with most research efforts being directed to cattle and shoats, among others.

The cow is the most important farm animal in parts of Africa. But climate change is threatening the existence of cattle. The difficulties of raising cattle when rainfall is scarce have seen some pastoralists across the entire country, not only in the traditional arid areas of north eastern Kenya, adopt camel husbandry in the last few years. The value of camels is now becoming increasingly acknowledged by Kenyan policymakers and researchers since climate variability has become a big challenge. The drought of 2005 to 2006 led to a $70 \%$ fall in the size of pastoralists' herds of cattle, goats and sheep. This situation left many pastoralists poor and, as a result, become dependent on relief food (Baird 2008, p. 4). This 
has led some Kenyans in northern Kenya to abandon cattle rearing in favour of camels. This includes the Rendille pastoralists, while the Borana are heading in the same direction, and the Pokot, Maasai and Samburu groups have begun to introduce camels into their cattle herds. Some development agencies such as Ewaso Nyiro Development Authority, Arid-lands, FARM Africa, Lands Resource Management, CARE-Kenya, Food for the Hungry Kenya and Kenya Agricultural Research Institute (KARI) have started to promote camel rearing in the ASAL of northern Kenya. Camels can contribute to food security, given the lower ability of cattle to withstand the harsh climatic conditions associated with climate variability. It was important to try and understand whether the Borana communities of Isiolo were ready to let go their cattle culture and embrace camel production, which could be the best bet option for reducing poverty and food insecurity in the dry lands of northern Kenya.

This study indicated that the Borana community of Northern Kenya had recently diversified their livestock; they now reared cattle, camels, goats and sheep. They used this as a coping strategy against disasters and calamities, as different herds have different water and pasture requirements and different resilience to drought and diseases. The diversity of the herds ensures risk distribution. For example, small stock - goats and sheep - have high fecundity and hardiness to drought, which make them suitable for post-drought reconstitution strategies.

\section{Study sites}

This work was conducted in three villages in Isiolo County, namely, Kambi Odha, Kambi Bule and Kambi Garba. These areas are occupied by pastoralists and agro pastoralists including Borana, Somali, Turkana, Samburu, Rendille and Ameru. This study focused only on the Borana community, although the others are important but the Borana are the largest group in Isiolo County.

\section{Methods}

A total of 400 respondents were interviewed, and the unit of study was household heads. This study collected both qualitative and quantitative data. Systematic sampling techniques were applied to select the respondents for the interviews, while purposive sampling was used to select focus group participants and key informants. Secondary data was collected from the literature, while primary data was gathered using questionnaires, focus group discussions, key informants and by direct observation.

Qualitative data derived from direct observations, focus group discussions and key informant interviews were presented in the discussions. Quantitative data derived from the household interviews were edited, coded and entered into a computer, and the Statistical Package for Social Science (SPSS) software version 20 was used for the analysis. Descriptive statistics were run to give frequencies and percentages on multiple-response questions.

\section{Results}

Type of livestock owned by the respondents

Most of the people interviewed had diversified livestock holdings (Figure 1). A total of $67 \%$ held at least four species of livestock (different combinations of cattle, camels, sheep, goats or donkeys), while $43.5 \%$ held camels in addition to other species. Of all the respondents, $1.8 \%$ said they had no livestock because these had died due to recurrent droughts and what was left was stolen by raiders. They were living as destitutes and relied on relief aid from the government and other development agents. Traditionally, the wealth of a Borana man was measured according to the number of livestock he owned, especially cattle. Those people who had no livestock were considered very poor, and the community used to loan them livestock. This community setting has been affected by climate variability as people now do not have enough to loan.

\section{Whether people have stopped rearing some livestock species due to climate variation}

More than half $(58.5 \%)$ of the respondents said they have not stopped rearing some livestock due to climate variability, while $41.5 \%$ of the respondents had stopped. On livestock which respondents have stopped rearing due to climate variability, some respondents said they have stopped rearing cattle since they do not survive for many days without water, and the respondents also indicated that since cattle are heavy feeders and they could not afford to provide forage for the cattle, in particular during drought periods. Others indicated that they had stopped rearing sheep because they cannot survive for many days without water. A few stated they have stopped rearing chickens as they die en masse due to diseases such as Newcastle disease.

\section{The most preferred livestock species}

The respondents were asked about the most preferred livestock species in the region. The majority of the respondents $(71.5 \%)$ replied that they preferred camels, giving as their reasons that camels are most suited for the region, as they can stay for many days without water and food (Figure 2). This agrees with Field (2005). Focus group discussions and key informant responses confirmed that camels have multiple purposes among the pastoral communities, which included providing transport in the desert, so many communities refer to camels as 'lorries' (trucks). Camels are also used for ecotourism and fulfil many social, religious as well as economic functions. Among other respondents, 22.3\% 


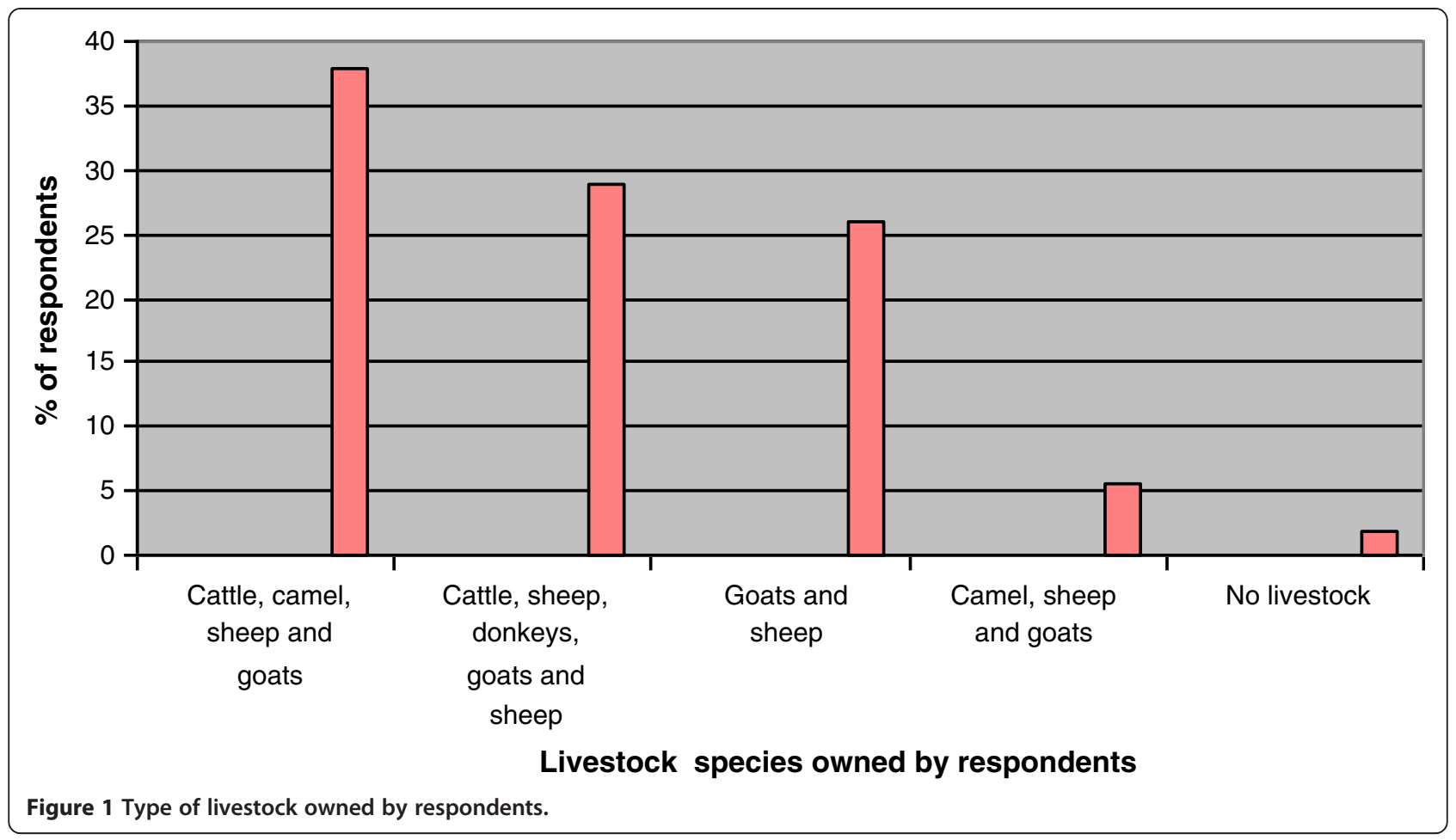

indicated that they would prefer goats and sheep because they can give birth twice per year, and they have twin births. They also noted that sheep and goat milk is used as medicine for ulcers and stomach-related problems. Shoats were compared to camels as they are both in the category of browsers, especially goats. Focus group discussions noted that shoats are easy and cheap to restock after a disaster. Only a small percentage $(4.5 \%)$ of respondents indicated they preferred rearing cattle. The reason given for this was that when cattle were sold, they were able to get more income as compared to selling other livestock species in the region.

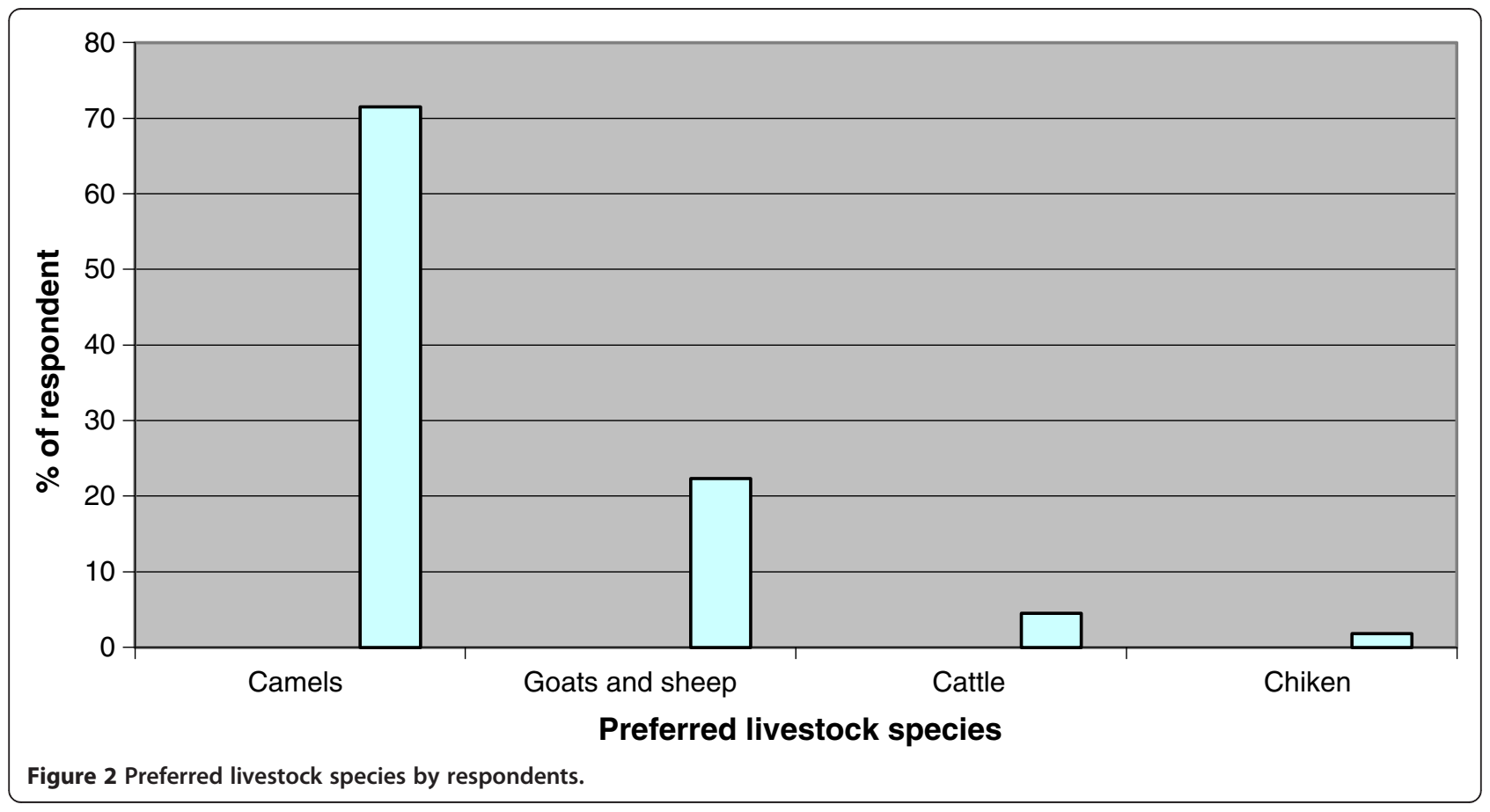




\section{Adoption of camel culture by the Borana pastoralists of Isiolo County}

This study found a trend among the Borana of Isiolo towards camel rearing. There is a shift from an old strategy that was socially and culturally centred on cattle pastoralism to new livelihoods that are more dependent on camels and small stock. According to the focus group discussions and responses from key informants, the Borana pastoralists used to be referred to as 'cattle owners' due to the attachment they had to cattle. Traditionally it was mandatory for every Borana household to own cattle and wealth was measured according to the number of cattle one had. Those who did not own cattle were considered the poorest and their relatives used to loan them female cows so as to build a herd. The Borana used to have a negative attitude towards the practice of rearing camels and used to associate it with inferior cultures. Focus groups and key informants reported that two clans among the Borana, the Karaiumbere and Aswa, used to consider it taboo for a person to have camels and to eat its products, namely milk and meat. This study found now that nowadays those two clans rear camels and use their products.

\section{Factors that lead to the popularity of camel production in the study site}

From the focus group and key informant discussions, this study found that camels are preferred due to many factors. Their adaptation makes them survive rainless seasons on the scantiest feed and exist in areas where other livestock species cannot survive. Camels and their products fulfil many socio-economic functions among the livestock keepers. Camel meat and milk is consumed by the pastoral communities, especially during the time of drought. Although camels are rarely slaughtered, during the dry season they are slaughtered and their meat is preserved, so that many households depend on the dry meat for a longer period. Camels produce 4 to 61 of milk per day, which is consumed by camel keepers whenever the camels are near the home sites, during dry and drought periods and some is sold which brings income to the households. When milk is plentiful, it is fermented into a product called mala. Camel milk is highly regarded by the camel keepers as it is believed to have medicinal value to cure various diseases such as diabetes, ulcers and stomach-related problems.

This study found that camel hides were important products, used both for domestic purposes and for sale. The hides were used to build the roofs for traditional pastoral houses. They were also used for making ropes, guards, drums, seats, sandals, prayer mats used by Muslims and water and milk containers. Camels are used as means of transport for camel keepers. They offer good means of transport to the pastoralists when migrating as they carry their household goods and the materials of their traditional houses. Camels carry old people, the ill, toddlers, pregnant women and those who have just given birth.

\section{Availability of forage for camel production}

The Borana pastoral communities have discovered that camels can also feed on anno (Euphorbia tirucalli) plants used to make live fences. This forage is available in Isiolo County in large quantities. The information gathered from focus group discussions and direct information indicated that the plant has become very popular as camel forage, and it is abundant in Isiolo town and Meru County, adjacent to Isiolo County. Camel keepers have been sourcing the forage from the neighbouring County, and this has promoted peri-urban camel rearing in Isiolo town.

\section{Constraints associated with camel rearing}

The respondents in this study reported that camel production is affected by diseases such as trypanosomiasis, camel pox, Rift Valley fever, pneumonia and ectoparasites. They also indicated that mastitis frequently interfered with milk production.

This study noted that the Borana persist in keeping indigenous camels which have low milk yields compared to Pakistan camels and Somali breeds which are considered to be superior to the local Borana camels. Their camels also take longer time to mature than the Somali camels and exotics. Little attention has been given to the improvement of camel husbandry in order to increase milk and meat production.

Another constraint to camel production which was identified by the study was insecurity in the study area. Livestock rustling, a cultural practice which has been used by most pastoral communities, has become frequent and more violent than it used to be, and this has led to increased fear among the Borana who complained that they produce camels for raiders to steal. This is very discouraging.

Furthermore, this study revealed that camels and their products have limited markets as compared to other livestock such as cattle and small ruminants. The reason for this is that there is very little domestic demand for camel products and most of the products are consumed by the camel-producing communities, while consumption of camel products by non-camel producing communities is limited. The Kenya Meat Commission, which deals with livestock meat production, does not deal with camel meat.

\section{Recommendations}

The study has shown the new role played by camel production in food security, response to climate variability 
and income generation. However, some factors interfere with the Borana community realizing the full social and economic importance of the camel. These factors include prevalence of camel diseases and the pastoralists' retention of less productive breeds. This study recommends that more resources be allocated towards disease control and introduction of improved breeds. Since camel products have limited markets as compared to other livestock species, the Kenya Meat Commission should expand its market to accommodate camel meat, in addition to cattle and small ruminant meat. Insecurity was also identified by respondents as a big problem, and this should be solved by the policymakers promoting peace between the Borana and other livestock keepers.

\section{Competing interests}

The authors declare that they have no competing interests.

\section{Authors' contributions}

AWK identified the research site, recruited the enumerators collected and analysed the data. JGW's contributions included data analysis and compiling and editing the work. Both authors read and approved the final manuscript.

\section{Authors' information}

AWK is a PhD candidate at the University of Nairobi. She is a Senior Research Officer at Kenya Agricultural Research Institute, working as a socio-economist. She has coordinated projects funded by the World Bank and European Union in the arid and semi-arid regions of Kenya. She has carried out policyrelated work, research, community development, university lecturing, and monitoring and evaluation with local and international organisations based in Kenya. JGW is a post-graduate student at the Catholic University of Eastern Africa. He was a project coordinator of SOS based in Nairobi.

\section{Acknowledgements}

Our deepest appreciation and gratitude is extended to the following people for their support in various capacities. The management of KARI is thanked for granting time to conduct this study. Special thanks goes to Mrs. Eunice Njoroge for her support while in the field. We are also grateful to our research assistants who helped us in data collection and all the informants who participated in the study.

\section{Author details}

'Socio-economics, Kenya Agricultural Research Institute, P.O. Box 147-60500, Marsabit, Kenya. ${ }^{2}$ Catholic University of Eastern Africa, P.O. Box 62157-00200, Nairobi, Kenya.

Received: 3 July 2014 Accepted: 13 August 2014

Published online: 28 August 2014

\section{References}

Baird, R. 2008. The impact of climate change on minorities and indigenous peoples. London: Minority Rights Group International.

Africa Farm. 2002. Micro-enterprise development. Best practices from FARM-Africa. Nairobi: FARM-Africa.

Field, C. 1994. Production from pastoralist systems in Kenya. In Marketing of pastoralist livestock products. Proceedings of the Kenya Pastoralists Forum Meeting 7th July 1994. Nairobi: KARI/ODA.

Field, CR. 2005. Where there is no development agency: A manual for pastoralists and their promoters. Aylesford: Natural Resources International.

Guliye, A. 2010. Peri-urban camel production in Northern Kenya: Opportunities and challenges. Proceedings of GrassNet Summer School Meeting 9th September 2010. Germany: University of Hohenheim.

Hulsebusch, C, and B Kaufmann. 2002. Camel breeds and breeding in Northern Kenya. In Proceedings of a collaborative research project on camel breed differentiation and pastoral camel breeding strategies within the KARI/EU Agriculture/Livestock Research Support Programme for Kenya (ARSP11; Project No.6 ACP KE 0161-KE 6003/001).

Kuria, S, and M Mbui. 2001. The camel and food security in northern districts of Kenya. In Proceedings of APSK 2001 Annual Symposium held on 7-8 March. Njoro, Kenya: Egerton University.

doi:10.1186/s13570-014-0013-6

Cite this article as: Kagunyu and Wanjohi: Camel rearing replacing cattle production among the Borana community in Isiolo County of Northern Kenya, as climate variability bites. Pastoralism: Research, Policy and Practice 2014 4:13.

\section{Submit your manuscript to a SpringerOpen ${ }^{\odot}$ journal and benefit from:}

- Convenient online submission

- Rigorous peer review

- Immediate publication on acceptance

- Open access: articles freely available online

- High visibility within the field

- Retaining the copyright to your article

Submit your next manuscript at $>$ springeropen.com 